\title{
Archival Knowledge: \\ Conceptual Frameworks for Recent Terminology in the KO Domain
}

\author{
Natália Bolfarini Tognoli*, Ana Célia Rodrigues**, \\ and José Augusto Chaves Guimarães***
}

*Universidade Federal Fluminense (UFF), Instituto de Artes e Comunicação Social (IACS), Departamento de Ciência da Informação (GCI), Rua Lara Villela, 126-São Domingos-

Niterói, RJ—CEP: 24210-590, Brazil, <nataliatognoli@id.uff.br>

**Universidade Federal Fluminense (UFF), Instituto de Artes e Comunicação Social (IACS II),

Programa de Pós-Graduação em Ciência da Informação (PPGCI), Rua Tiradentes, 148-Ingá-

Niterói, RJ—CEP: 24210-510, Brazil, <anyrodrigues@yahoo.com.br>

***Universidade Estadual Paulista (UNESP), Faculdade de Filosofia e Ciências-

Campus de Marília, Departamento de Ciência da Informação (DCI), Avenida Hygino Muzzy Filho, 737_

Bairro Mirante-Marilia/SP_CEP: 17.525-900, <chaves.guimaraes@unesp.br>

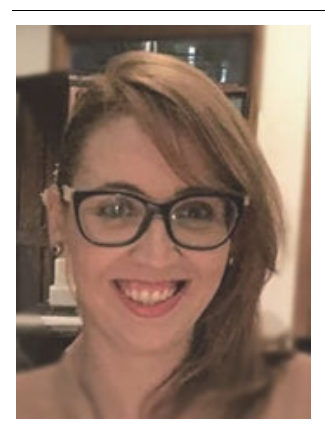

Natália Bolfarini Tognoli is Professor at the Department of Information Science at Fluminense Federal University (UFF), Brazil, and at the Information Science Graduate Program (PPGCI) at the same institution. She is a member of the Brazilian ISKO Chapter. Her main research interests include archival knowledge organization, contemporary diplomatics, social epistemology and social justice in archives.

Ana Celia Rodrigues is Professor at the Department of Information Science at Fluminense Federal University, UFF, Brazil, and coordinates the Information Science Graduate Program (PPGCI) at the same institution. Her main research interests include contemporary diplomatics, archival identification, appraisal, classification, record management and city archives.

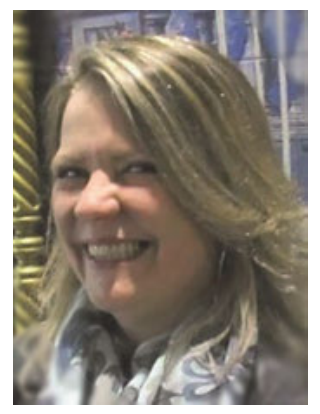

José Augusto Chaves Guimarães is Professor at the Department of Information Science at São Paulo State University, UNESP, Brazil. He is a 1-B CNPq researcher, founder and former president of the Brazilian ISKO Chapter and former member of the ISKO Executive Board (2012-2016). His main research interests include knowledge organization, epistemology of information science, information ethics, juridical information, bibliometrics and scientometrics.

Tognoli, Natália Bolfarini, Ana Célia Rodrigues and José Augusto Chaves Guimarães. 2019. “Archival Knowledge: Conceptual Frameworks for Recent Terminology in the KO Domain.” Knowledge Organization 46(7): 522-529. 23 references. DOI:10.5771/0943-7444-2019-7-522.

Abstract: Despite having the principle of provenance as its guiding element, the archival knowledge organization still prescinds, for conceptual purposes, of greater clarity of its object- the archival knowledge- a fundamental aspect for the sedimentation of the archival studies and of its discursive community in the scope of KO. This article aims to define a conceptual framework to archival knowledge by using Dahlberg's concept theory. In this vein, it established the nominal concept or definiendum — archival knowledge — seeking to analyze its real definition, composed by three inseparable definiens: the concept of fonds, the knowledge of documentary form and the knowledge of document creation context. At the end, it demonstrates that archival knowledge can be defined as being a reunion of three indivisible facets in which the archival bond will be contemplated.

Received: 28 April 2918; Revised: 9 July 2019; Accepted: 9 August 2019

Keywords: archival, documents, knowledge, concept, context 


\subsection{Introduction}

Recently, archival science, which has been linked for years to the historical, administrative and diplomatic fields, is getting closer to the disciplines that have recorded information and knowledge as their object of study, finding in the fields of information science and knowledge organization a space for interlocution, especially from what has been defined by Tognoli, Guimarães and Tennis (2013) as archival knowledge. Knowledge organization $(\mathrm{KO})$ constitutes an effective interdisciplinary locus (García Marco 1995; Hjørland 2008) in which fields such as information science, logic, linguistics, communication, among others, are integrated in terms of theoretical and methodological frameworks that foster the development of processes, products and instruments regarding the representation and organization of documents and of their informational contents, both by persons and by programs. In the 1990s, Esteban Navarro (1995) proposed an approximation of the archival studies to knowledge organization, considering the latter an integrating field, and defending the participation of discussions about archives within the knowledge organization scientific societies and congresses, once the archival documents are also classified and described. However, only after two decades, this issue emerged more strongly when Guimarães and Tognoli (2015) restored the discussions about archival science within $\mathrm{KO}$ on their paper about the principle of provenance as a new domain analysis approach, in which they added the provenance studies to Hjørland's eleven approaches (2002). By proposing the principle of provenance as a domain analysis approach, they justified the characterization of archival KO as a domain itself. This domain is composed by a set of researchers from different parts and institutions of the world who integrate an invisible college_-or epistemic community as pointed out by Meyer and Molineux-Hodgson (2010)—deeply involved in building an epistemological basis by using a specific discursive structure that merges traditional archival terminology with LIS terminology. Notwithstanding the fact that archival knowledge organization has the principle of provenance as its guiding element, it still prescinds, for conceptual purposes, of greater clarity of its object-archival knowledge - a fundamental aspect for the sedimentation of archival studies and of its discursive community in the scope of $\mathrm{KO}$.

Dahlberg (1978, 143 emphasis original) defined a concept as "a knowledge unit, comprising verifiable statements about a selected item of reference, represented in a verbal form." So, it could be understood that a definition stems from the establishment of a kind of "equation of meaning" where it can be observed, on the one hand, the element to be defined (definiendum), which is understood herein as archival knowledge and, on the other hand, the defining text that establishes one or more meanings of that element (definiens). In this context, Dalhberg (1978, 149) emphasizes the difference between nominal definitions, "concerned with the 'nomen,' the term, and its meaning" (i.e., archival knowledge), from real definitions that delimit the intention of a certain concept, that is, of what it is made of, distinguishing it from others with identical characteristics. Hence, while the nominal definition concerns the name, the real definition has the purpose of presenting the knowledge contained in a certain concept. Once established, the nominal concept or definiendum - archival knowledge- this article aims to analyze the concept's real definition, which is believed to be composed of three definiens.

\subsection{Archival knowledge: conceptual frameworks}

A concept can be understood as a set of true statements about a given object, fixed by a linguistic symbol. According to Dahlberg (1978), at the concept level, each statement presents a predictable element of the object that may be called "defining characteristics or knowledge elements" $(1978,150)$. In order to understand how a scientific-disciplinary universe is theoretically formalized, it is necessary to know the concepts that support scientific theory.

Rabello (2008) stated that if we apprehend the concept within logic and scientific reason, it could be defined as being the necessary delimitation on which scientific language rests to represent the reality through a symbology created by the primacy of accuracy, sensitivity and consensus (intersubjective), in the search of representing the phenomena of reality.

When defining a concept, essential presuppositions are established in argumentation and verbal communications, which are elements required for the construction of scientific systems. The importance of definitions is also evident when one considers the international communication of knowledge (Dahlberg 1978). According to Hjørland (2009), a concept is a reflection of scholars' methodological ideals. In this respect, a defined concept is believed to be an important indicator of behavior of a given scientific community (Rabello 2008) due to the fact that it is the result of a systematized theorization that consolidates it in a certain historical context and expresses the forms of thought, social practices, professional practices, etc.

By means of this paper, we consider the concept of archival knowledge as being dynamically and socially constructed, stabilized by archival science and diplomatics standardized practices. Hjørland states (2009, 1522):

Concepts are dynamically constructed and collectively negotiated meanings that classify the world according to interests and theories. Concepts and their development cannot be understood in isolation from 
the interests and theories that motivated their construction, and, in general, we should expect competing conceptions and concepts to be at play in all domains at all times.

Based on a "post-Kuhnian view of concepts" Hjørland explored concept theory and suggested that the major epistemologies (namely, empiricism, rationalism, historicism and pragmatism) are the best way to understand and classify theories of concepts. Empiricism defines concepts by clustering similar objects; rationalism defines concept by a set of primitive given concepts; historicism defines concept genealogically and by relationships; and, pragmatism defines concept by deciding which class of things best serves a given purpose and then to fixate this class in a sign (Hjørland 2009).

In face of this context, when seeking a definition of archival knowledge, as proposed in the beginning of this paper, the content of this particular concept is intended to be set by limiting it, based on archival and diplomatic theory in a specific context of time and interest, following a pragmatic perspective of concept theory. Hjørland states (2009, 1526 emphasis original):

Pragmatism understands concepts as a way to fixate parts of reality in thought, language, and other symbolic systems. These parts of reality are not fixated just by similarity (as assumed by empiricism), by logical division (or similar rules as assumed by rationalism), or by genealogy (as supposed by historicism), but by what is considered to be functional equivalent classes of things.

According to Dahlberg (1978), defining a concept is equivalent to stablishing an "equation of meaning" where, on the one hand (on the left), lies what must be defined (the definiendum), and on the other hand (on the right) what something is defined for (definiens). Still according to Dahlberg, the definitions can be nominal or real. The first is about setting the meaning of a word (e.g., archival knowledge), and the latter delimitates the intention of a specific concept, in other words, what it is made of, distinguishing it from others with identical characteristics. Both definitions can be distinguished by saying that the nominal definition aims to fix the use of a certain word while the real definition is intended to present the knowledge contained in a certain concept (Dahlberg 1978). Once the nominal concept is defined-the archival knowledge — as setting the use of the word — we now turn to its actual definition, which is believed to be composed of three definiens, or frameworks: the concept of fonds, the knowledge of documentary form and the knowledge of record creation context.

\subsection{The first definiens: the concept of fonds}

In 2013, in the paper "Diplomatics as a Methodological Perspective for Archival Knowledge Organization," Tognoli, Guimarães and Tennis $(2013,205)$ defined archival knowledge as:

all the knowledge produced by a particular person or entity and grouped into fonds ... the creator (or author), who is the physical or juridical person responsible for the creation of records; the user, who will use the record to evidential or administrative ends or to historical purposes, and the intermediaries, who are the archivist or other persons responsible for the organization of records.

One can observe that the concept of fonds is the first definiens of the archival knowledge, since it gathers in itself all the information about a certain person or entity, reflecting the knowledge generated in previous stages, as the application of the diplomatic method at the time of archival identification.

The concept of fonds was established in 1841 by Natalis de Wailly, due to the need to solve the accumulation problems inside the National Archives in France. The concept was established within the principle called respect des fonds, according to which the records produced or accumulated by one person or entity should be grouped together. For Duchein $(1983,64)$, "the simplest definition of respect des fonds means to group, without mixing them with others, the archives (documents of every kind) created by or coming from an administration, establishment, person, or corporate body."

In 1881, in Prussia, the principle of respect des fonds was broadened and the Provenienaprinzip (principle of provenance) was enunciated-according to which public records should be grouped following the administrative units that create them. "In the same period the principle Registraturprinzip is announced, according to which the records of every agency should be maintained in the archival institution in the order given to them by the registry office and should not be reorganized by subject-matter groups" (Tognoli and Guimarães 2019, 10). Therefore, the principle of provenance can be considered an enlargement of the principle of respect des fonds, once it encompasses two levels of provenance: the respect of producer and the respect of original order.

According to Tognoli and Guimarães, despite a conceptual terminological confusion in the literature regarding the principle of provenance, it is a consensus that records are products of activities developed by individuals or entities and to understand this means to understand the network of relationships among objects (records), agents 
(producers) and functions. Therefore, a record (or archival document) should not be conceived as an isolated element. Understanding a record means knowing exactly who created it, in which structure and under which procedure. In other words, what are its origins, to whom, when and where. According to Duchein (1983), the answers to these questions lie in the knowledge of the documentary background, in the comprehension of its totality.

The idea of fonds as archival knowledge becomes clear at this point. One may notice that the reunion of records that came from the same provenance integrate a set of records that contain a particular knowledge about a specific person or institution. Notwithstanding, we understand this reunion as a final moment, a result of a series of procedures that enable the archivist to gather this specific knowledge into fonds (first definiens). Therefore, we introduce the knowledge of the documentary form-achieved by diplomatic analysis - as the second definiens of the concept of archival knowledge, understanding it as essential to comprehend the set of records that will constitute the fonds.

\subsection{The second definiens: the knowledge of the documentary form}

In a new reality of production, organization and use of information, it is essential to establish the reasons behind the record creation, the relation between it and its creators and, thus, the intentions behind the action of recording the information. Hence, the study of the record based on diplomatics and its method becomes the most recommended to the archivist. Being able to establish who produced it, why and for what reasons, through the study of documentary form, is the great contribution of the diplomatics to the documentary contemporary archival studies.

Diplomatics is a middle age discipline whose main purpose has always been distinguishing false documents (urkunde, acte) from authentic ones. The diplomatist's objective was to analyze documents that served as testimony for the verification of facts, sometimes under a practical-juridical objective, sometimes under a historical perspective. To do so, it became necessary, first and foremost, to study the document form.

In this context, we can understand diplomatics as a critical art that aims by means of understanding of the documentary form to discern the authenticity of a document. Specifically regarding documentary form, it can be said that it structures the document providing the necessary elements and rules of composition so that a particular juridical act can be recognized as suitable for the performance of its function. Thus, the diplomatic document will have the same form when the same juridical act occurs. This form will be determined by rules established by law and, according to Duranti $(1989,15)$, "will reflect political, legal, administrative, and economic structures, culture, habits, myths, and constitute an integral part of the written document, because they formulate or condition the ideas or facts which we take to be the content of the documents."

The documentary form is all that is conditioned by rules. These rules will determine the intrinsic and extrinsic elements of the document, that is, the text itself, and the characteristics that will give the document evidential value, as well as the means of writing it. The form is, therefore, decisive for the creation of a juridical and relevant document. Duranti (1991) stated that it reveals and perpetuates the function of a document. According to Sickel (1867), the form of diplomatic document must follow a structure composed by (initial) protocol (which contains the administrative context of the action), text (which contains the action) and eschatocol or final protocol (which contains the documentation context of the action). The protocols act as a frame for the document, whereas the text presents the content itself.

Sickel also defined diplomatics' object of study following the German word Urkunde, which means a testimony written according to a specific variable form regarding the place, time or person, about a juridical fact (Sickel 1867). The definition of an object (Urkunde) and the division between text and protocols recommended by Sickel allowed diplomatics to establish its own method of document analysis, elevating it to the status of discipline. However, notwithstanding the great importance of Sickel's method to the discipline's development, its application until the first half of the twentieth century was limited to single medieval documents.

In 1961, Robert-Henri Bautier, French historian and archivist, advocated in favor of expanding the object of diplomatics beyond those testimonies written according to the observation of certain forms, expanding it to all archival documents, without chronological or juridical limitation. The author stated that the documents should be understood as part of an archival fonds_-as an archival document - which would offer a better comprehension of the context in which the document was created, since the sources would be clearly larger.

Still, according to Bautier, a document could not be truly understood outside the context to which it belonged. As archivists are very clear about this relationship between the documents and their fonds, the diplomatists should also rely on the fonds perspective offered by archival science. The author stated (Bautier 1961, 212) that "the critique of the documents is surprisingly facilitated by their approach to the documents before and after them ... the diplomatic document is essentially an archival document, that is, a piece in a set, an element in a fonds." 
The perspective of a more contemporary discipline, focused on archival documents, found a space in the coming discussions about the production, organization and preservation of documents in a new technological context. Bautier's defiance to a more suitable discipline laid the foundations to the application of diplomatic method to contemporary archival documents, including the digital ones. In 1987, the theoretical and methodological contribution of diplomatics to archival science was supported by the studies of Paola Carucci who extrapolated the limits of study of the diplomatics field, applying its method to the contemporary Italian public administration documents. The author argues the current tendency to expand the concept of document beyond the limits of the relationship with the strictly juridical nature of its content. According to Carucci $(1987,29)$, "this tendency, which leads to an extension of the diplomatic purposes of the analysis of the document (and its procedures) for the study of the institution that produces it, finds — at the same time - a justification in the theoretical evolution of the archival science." The author also reinforces the idea of common object among disciplines when she writes (Carucci 1987, 27) that "diplomatics studies the single record, or, if we prefer, the elementary archival unit, document ... analyzing, above all, its formal aspects in order to define the legal nature of acts, whether in relation to their genesis or in relation to their effects."

The justification of a shift from the point of view of diplomatics' purposes lies in the fact that, contrary to what has been studied up to now, diplomatics no longer has the sole and exclusive role of identifying the elements of the document to verify its authenticity. With the evolution of the law and a different conception of the state, the legal principles were modified, as well as the relevance of certain elements used to legitimize the documents. In other words, the diplomatics of the contemporary document is no longer limited to establishing the characteristics of an authentic document, discovering a new purpose in the field of archival studies when proposing the observation of the context in which documents are created, from an analysis of the part to the whole.

Two years later, in 1989, Luciana Duranti proposed new uses for diplomatics, from the application of the diplomatic method to contemporary documents in North America. The author states that it is not necessary to reformulate the set of diplomatics concepts and method of medieval documents to apply it to the contemporary ones. According to Duranti (1989), in order to apply the diplomatic method to contemporary documents it is necessary to adapt it since the application now rests on archival documents that have a contextual relationship with each other.

Diplomatics, in the context of archival science, allows the archivist to come to an understanding of the documen- tary set and its context from the critique of the document. Thus, the archivist's analysis shifts from the immediate documentary context of the material she/he examines to the broader functional context of the creators of the document and their relationships (Duranti 1989). This analysis, as well as the critique of a medieval document, is made through the study of the documentary form, which is manifested in its internal and external elements.

Buckland's article on document theory (2018) states that any interaction or shared attribute can be used to indicate a relationship that will provide the meaning of a document. In this vein, the study of elements presented in the documentary form, especially the intrinsic ones, will indicate three important relationships: the one between the record and the procedure that created it, which means its organic nature, another one between the internal elements themselves - the diplomatic discourse - composed by the protocols and the text, achieving a harmonic discourse that will give the document a meaning, and the relationship between the set of records that belong to the same function and documentary form that will give birth to record series (a set of records with the same specific kind of information that helps carry out the same activity).

Tognoli (2014) elaborated a guide for the analysis of documents from a comparison of the diplomatic methods proposed over the centuries (Mabillon 1681; Sickel 1867; Duranti 1989) and came to what she called an ideal method of diplomatic analysis for archival documents as shown in Table 1.

In the proposed model, the first element identified is the document type, or genre, which is the means by which the action is recorded. According to Camargo and Bellotto (1996), the document type is the configuration a document assumes according to the disposition and nature of the information contained therein. Bazerman (2012) calls it document genre. According to Bazerman (378), "the documents took shape in evolving genres within historically changing social systems." Then, the first thing the archivist must identify is the type/genre, since it will be determinant to know the documentary form. To Bellotto (2004), each of these documents also contained specific kinds of information that helps carry out the activity that is called name of act, which is the configuration that assumes a genre, according to the activity that generated it. The documentary function refers to the legal and juridical value of the document content. A dispositive document is the one that is created to enforce and validate the action, while the probative simply attests to a legal/juridical fact that is already complete, perfectly valid before its documentation. The informative document clarifies the issues and/or information contained in other documents. The nature of act is also important at the moment of document analysis, since it defines the relationship between the document and its 
N. Bolfarini Tognoli, A. C. Rodrigues, and J. A. Chaves Guimarães. Archival Knowledge

\begin{tabular}{|l|}
\hline Model of diplomatic analysis for archival documents \\
\hline Document Type (genre) \\
\hline Name of act (function + type of document) \\
\hline Documentary function: dispositive/probative/informative \\
\hline Nature: public or private \\
\hline Extrinsic elements: material/type of writing/quality of impression/medium/special signs \\
\hline $\begin{array}{l}\text { Intrinsic elements: language/style/Protocol (Title/subject/dates/inscription-author's name and addressee's name)/ } \\
\text { Text (disposition)/Eschatocol (dates/attestation/signatures) }\end{array}$ \\
\hline $\begin{array}{l}\text { People involved in the creation of document: authors (of action and of document)/addressee (of action and of } \\
\text { document)/write/testimonies. }\end{array}$ \\
\hline Status of transmission: pre-original/original/post-original \\
\hline Complementary information: name of the fonds to which the document belongs/group/records series. \\
\hline
\end{tabular}

Table 1. Model of diplomatic analysis for archival records (source: Tognoli 2014).

author. A document is considered public when it is created by or on behalf of a public person, exercising a legal activity in the public context. On the contrary, a document is private if it is created by a private person, or in its name, in the legal system in which it acts.

The extrinsic elements are divided into material (support) and format. The types of writing include hieroglyphics, cuneiform, romanic, arabic, gothic, etc. The print quality is intended to provide a better detail of the physical conditions of the document, analyzing if it has erasures or deteriorations, for instance. Seals and signs, such as the authentication stamps, or the protocol registry and classification number, or electronic signatures, are considered as external elements due to the fact that they have been placed after the document was created.

Duranti (1989) defines the intrinsic elements of documentary form as the integral components of its intellectual articulation, the mode of presentation of the document. The analysis of the three-part division in protocol, text and eschatocol, enables the archivist to understand the administrative context of the action (through the identification of the author, addressees, title and dates of the document), the action in which the document participates through the analysis of the disposition in the text (the function) and the documentation context of the action (means of validation, signatures, indication of competencies and responsibilities).

The identification of the people involved in the creation process of the document is important since they are the subjects of duties and rights involved in the legal system in which the document is created. By identifying the authors, addressees, writers and witnesses, the relations between them and the legal system in which they work are evidenced, providing a more detailed study of the context in which these documents are created.

The status of transmission determines the degree of authority of the document and, for that reason, its identi- fication is paramount in the diplomatic critique. The original document, for instance, will have much greater value and weight than the draft or copy due to the fact that it is the first and perfect. The draft is a preparatory document which has no juridical value. The post-originals are the copies, usually divided into simple copies, authorized copies or imitative copies. Finally, there are the complementary information that will be useful to the archival context, since it is possible to identify the fonds, groups and series to which the document belongs to.

Therefore, we understand that the application of the diplomatic method provides essential elements so that the archival document can be known beyond its form, allowing an approximation with its production context and nature. Diplomatic criticism proceeds from the form of the document to the act initiated or referred to by the document, which is defined as documentary typology. According to Duranti (1991), this analysis aims at understanding the juridical, administrative and procedural context in which the documents under examination were created.

Rogers (2015) understands diplomatic analysis as a process of abstraction and systematization, where one deconstructs a document in order to identify and locate elements that reveal its provenance, relationships, reliability and authenticity. Archivists, therefore, begin to understand the diplomatic method as a new tool to help the management of the documentation generated in administrative processes.

In a new reality of information production, organization and use, it is important to establish the reasons behind the creation of records, the relationships between them and their creator and the intentions behind the action of recording the information. To do so, the analysis of the archival document, based on and its method becomes one of the safest ways for the archivist to understand it. Being able to establish who produced it, why and for what reason, through the study of the documentary form, is the great contribution of diplomatics to current archival studies. 
We can conclude that, from the study of documentary form, the archivist is able to examine the context and the procedures for the creation of the document to determine the existing relations between them. The results obtained through diplomatic analysis will subsidize the processes of organization and representation, since we believe that the information collected during this process, once amalgamated and understood in a specific context, constitutes an archival knowledge, that is, a knowledge acquired from the study of the document and its relations with the creator and the procedure that generated it.

In this regard, we point out the knowledge acquired from the study of documentary form as a second definens of the concept of archival knowledge that will be completed from the methodology of archival identification, which will enable the generation of the third definiens of the concept, the knowledge of record creation context, as presented in the next section.

\subsection{The third definiens: the knowledge of record creation context}

Due to the need to rationalize the production of records and to organize and eliminate documents produced by public and private administrations after World War II, several commissions were established in the United States in order to propose some solutions to the problem of document accumulation. These actions, supported by the Hoover Commission and by the Federal Records Act gave rise to record management programs, which have changed considerably the archival practice all over the world. According to McLeod and Lomas $(2015,346)$ "a twentieth-century construct, record management is concerned with the processes and controls for the creation, capture and management of an organization's records to support that organization's operation." These operations aim to control the document from the moment of its production until its destination. Record management can be characterized as a set of procedures applied to control the archival documents throughout its life cycle, focusing on the moment of production and accumulation in the first and second age. Still, according to McLeod, the introduction of record management programs in archival theory led to the need to create methodologies to solve the problems observed in archives.

It is in this context that the methodology of archival identification arises in Spain, by the 1980s, as a tool for analyzing the archival document and its producing entity, applied to the masses of accumulated documentary, aiming at the elaboration of proposals for the evaluation and classification of archival documents. Rodrigues (2015) states that the identification is a research activity with two main objects of study: the producing entity and the archival document. Therefore, the archival identification methodology is about researching the elements that characterize these two objects: the producer entity, analyzing the organic (administrative structure) and the functional elements (competencies, responsibilities, functions and activities), and the documentary typology, which is identified through the application of a diplomatic method (the name of the act and its relationships with the procedure). Rodrigues (2008) stresses that the need to identify the archival document in its creation context in order to plan its creation/production and the technical treatment for the accumulation of documents led the field to a reflection on the identification as an archival process and the discussions about the place it takes in the scope of archival methodologies.

The archival identification is considered an intellectual activity aiming to determine the identity of archival documents, recognizing the elements that distinguish it in its whole (Rodrigues 2015). In order to recognize these elements, the archivist makes use of documentary analysis, supported by the diplomatic method-searching the document type and the name of the act-and the contextual analysis that is subsidized by the study of the information about the producing entity (information collected in regulations, statutes, organization charts) to determine its organic elements (administrative areas representing it) and functional elements (competencies, functions, activities). The specific knowledge generated from the information collected on the producing entity along with the process of document analysis, both supported by the methodology of archival identification, is believed to be the third and last definiens of the concept archival knowledge. The outcome of this methodology will enable the archivist to recognize the archival bond that places a record in context and gives additional meaning to the record, including the relationships between records that relate to a specific transaction as well as the relationship between the records of preceding and subsequent transactions (InterPARES Glossary 2002).

\subsection{Conclusion}

We aimed to approximate archival studies to knowledge organization, since we considered the latter as an integrating field that can contribute to the processes of organization in the archival domain (especially to classification and description processes). In order to accomplish this main goal, we intended to define the archival knowledge concept, once we understand that the processes of archival classification and description focus on it.

Based on a pragmatic perspective, considering the concept as sign representing functional equivalent classes of things and using Dahlberg's equation of meaning to understand it, we found out that archival knowledge (nominal definition) can be conceived from the combination of three inseparable definiens, according with the following 
N. Bolfarini Tognoli, A. C. Rodrigues, and J. A. Chaves Guimarães. Archival Knowledge

equation of meaning: definiendum $=\operatorname{def} 1+\operatorname{def} 2+\operatorname{def} 3$, where:

archival knowledge $=$ the concept of fonds + the knowledge of documentary form + knowledge of record creation context.

Finally, we can consider archival knowledge as being all of the knowledge gathered together in a fonds, produced by the archival identification, from the analysis of documentary form and the record context of creation. The information collected throughout the application of the diplomatic method to analyze the documentary form and through the theoretical bases of law and administration to study the producing entity structure and functioningwhich is an outcome of the methodology of archival identification-will constitute a specific knowledge about the fonds. In this vein, archival knowledge is defined as being a reunion of three indivisible facets in which the archival bond will be contemplated.

\section{References}

Bautier, Robert Henri. 1961. "Leçon d'ouverture du cours de diplomatique à L'ecole des Chartes." Bibliothèque de l'ecole des Chartes 119: 194-25.

Bazerman, Charles. 2012. "The Orders of Documents, the Orders of Activity, and the Orders of Information." Archival Science 12: 377-88.

Bellotto, Heloísa Liberalli. 2004. Arquivos permanentes: tratamento documental. 2nd ed. Rio de Janeiro: FGV.

Buckland, Michael. 2018. "Document Theory." Knowledge Organization 45: 425-36.

Carucci, Paola. 1987. Il documento contemporaneo: diplomatica e criteri di edizione. Roma: La Nuova Italia Scientifica.

Dahlberg, Ingetraut. 1978. "A Referent-Oriented, Analytical Concept Theory for INTERCONCEPT." International Classification 5: 142-51.

Duchein, Michel. 1983. "Theoretical Principles and Practical Problems of Respect des Fonds in Archival Science." Archivaria 16: 64-82.

Duranti, Luciana. 1989. "Diplomatics: New Uses for an Old Science (Part I).” Archivaria 28: 7-27.

Duranti, Luciana. 1991. "Diplomatics: New Uses for an Old Science (Part VI).” Archivaria 33: 6-24.

Garcia Marco, Francisco Javier. 1995. "Fundamentos de organización y representacíon documental: aportaciones de la archivística." Revista general de información y documentación 5: 91-148.
Guimarães, José Augusto Chaves and Natalia Bolfarini Tognoli. 2015. "Provenance as a Domain Analysis Approach in Archival Knowledge Organization." Knowledge Organization 42: 562-9.

Hjørland, Birger. 2008. "What is Knowledge Organization (KO)?" Knowledge Organization 35: 86-101.

Hjørland, Birger. 2009. "Concept theory." Journal of the American Society for Information Science and Technology 60: 1519-36.

InterPARES 2 Project. 2019. “Terminology Database." Accessed April 5. http:// http://www.interpares.org/ Ip2/Ip2_Terminology_Db.Cfm

McLeod, Julie and Elisabeth Lomas. 2015. "Records Management." In Encyclopedia of Arcbival Science, ed. Luciana Duranti and Patricia C. Franks. London: Rowman \& Littlefield, 346-9.

Meyer, Morgan and Susan Molyneux-Hodgson. 2010. "Introduction: The Dynamics of Epistemic Communities." Sociological Research Online 15: 1-7.

Rabello, Rodrigo da Silva. 2008. "História dos conceitos e ciência da informação: apontamentos teórico-metodológicos para uma perspectiva epistemológica." Encontros Bibli: Revista Eletronica de Biblioteconia e Ciência da Informação 26: 17-46.

Rodrigues, Ana Célia. 2015. "Identificação como requisito metodológico para a gestão de documentos e acesso à informações na administração pública brasileira." Ciência da Informação 42: 64-80.

Rogers, Corinne. 2015. "Diplomatics of Born Digital Documents: Considering the Documentary Form in a Digital Environment." Records Management Journal 25: 6-20.

Sickel, Theodor Von. 1867. Acta regum et imperatorum Karolinorum digesta et enarrata: Die Urkunden der Karolinger. Wien: Gerold's Sohn.

Tognoli, Natalia Bolfarini, José Augusto Chaves Guimarães and Joseph Tennis. 2013. "Diplomatics as a Methodological Perspective for Archival Knowledge Organization." In Proceedings from North American Symposium on Knowledge Organization. Vol. 4, 216-27. doi:10.7152/nasko.v4i1.14 661

Tognoli, Natalia Bolfarini. 2014. A construção teórica da diplomática: em busca de uma sistematização de seus marcos teóricos como subsídio aos estudos arquivísticos. São Paulo: Cultura Acadêmica.

Tognoli, Natália Bolfarini and José Augusto Chaves Guimarães. 2019. "Provenance." Knowledge Organization 46: 55868. 